\title{
Mapping Of Forest Cover through Remote Sensing and Geographical Information System (Gis), Wokha District, Nagaland
}

\author{
Wangshimenla Jamir \\ Department of Geography Nagaland University
}

\begin{abstract}
The economy and social well being of the people in the state have remarkable depend on forests and its cover. The relevance of this sector is all the more pronounced in the Wokha area, which has a predominantly agricultural based rural economy. The mainstay of the rural people accounting for nearly $70 \%$ of the total state population is on agriculture. Biological resources in the study area hold great promise in terms of potential for providing material needs and environmental services.
\end{abstract}

Key words: Forest cover, types of forests, Remote sensing and GIS

\section{Introduction}

Importance of Forests is globally recognized as an important source of subsistence, employment, revenue earnings and raw materials for the industries, and for the vital role they play in maintaining ecological balance, environmental stability, biodiversity condition, food security and sustainability of resources of a country. These have to be managed judiciously not only for environmental protection and other services but also for various products and industrial raw materials. Considering the crucial role that forests play in the country's ecological stability and economic development, the current National Forest Policy aims at maintaining a minimum of 33 percent of country's geographical area under forest and tree cover. This requires periodic monitoring of the forest cover of the country for effective planning and sustainable development.

There appears to be no efforts at National level prior to 1910 for mapping and monitoring of forests, though forest maps were available at local level mostly in the working plan documents of State Forest Departments. Even Survey of India carried out forest survey and mapping at scales decided by Superintendent of Survey with the forest departments. After 1910, forest surveys were made ancillary to topographical surveys. In 1976, National Atlas and Thematic Mapping Organization (NATMO), published Forest Atlas of India depicting administrative and forest boundaries. These maps, however, did not depict the actual forest cover in the country since all legal forest areas did not necessarily contain forest crop. Forest Survey of India (FSI), an organization under the Ministry of Environment \& Forests (Government of India) was mandated in 1986 to monitor and map country's forest cover on biennial basis. Consequently, FSI has been carrying out assessment of forest cover in the country using satellite based remote sensing data and has been publishing its findings in State Forest Report (SFR) every two years. Remote Sensing technology has provided users the means to create numerous maps quickly and efficiently, subject to quality and resolution of data. FSI has carried out forest cover mapping of Nagaland mentioning 7 districts upto 1999, and 8 districts of Nagaland since 2001.There are now there 11 administrative districts in the state. The present study covers the mapping of forest cover in Wokha districts of Nagaland.

\section{Study area}

Wokha area situated in the northern part of the state it is the traditional home of the Lotha-Naga. It is surrounded by Mokokchung and Zunheboto district in the north and northeast, Kohima district in the south and southwest. It has the state boundary with Assam in the west and southwest. Wokha district of Nagaland lies between $26^{\circ} 8^{\prime}$ North Latitude and $94^{\circ} 18^{\prime}$ East Longitude covering a geographical area of $1628 \mathrm{Sq} . \mathrm{Km}$, is situated at about $1,500 \mathrm{~m}$ above sea level. It has a total population of 1,66,239, according to Census handbook, 2011. The people of the district mainly practise Jhum cultivation. It is the homeland of the Lotha Naga tribe and like the other districts of Nagaland the topography is hilly with ridges and ranges dissected by seasonal streams and rivers. As per the ground water resources estimation of the state, out of a total area of 1,62,800 hectare, about 8,710 hectare is considered hilly area and about 1,500 hectare is earmarked as valley area like Baghty. The district has three ranges based on the topography, namely the Wokha or upper range, the Sanis or middle range and the Bhandari or lower range (District census handbook, Wokha 2001)

\section{Data product used}

- Survey of India, Topographical maps of Wokha Index, at the scale of 1: 50,000 
- $\quad$ Survey of India Guide Map of Nagaland on the scale of 1: 20000

- The Multi Season digital Data of IRS-P6 LISS-III Jan.2006 \& IRS-P6 LISS-III Jan.2008 (resolution 23.5m) acquired from National Remote Sensing Centre (NRSC), Hyderabad.

Fig.1: Geo-referenced map,Wokha

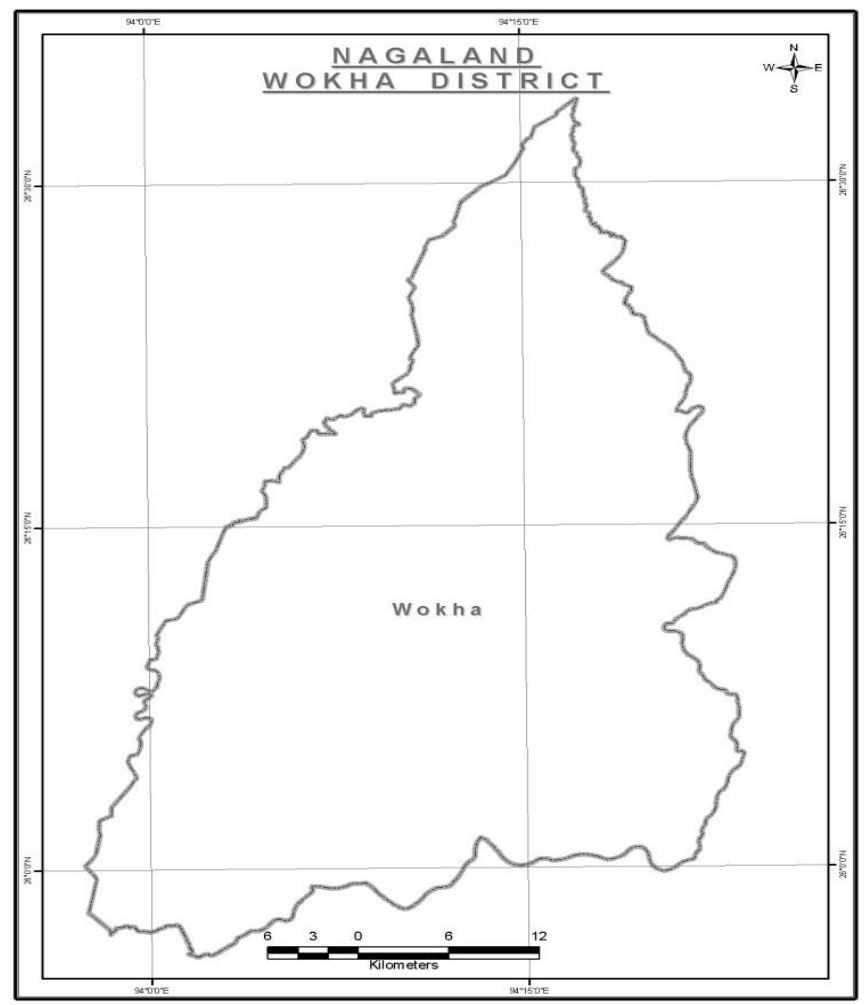

Fig. 2: Digital Data of IRS-P6 LISS-III Jan.2006, Wokha

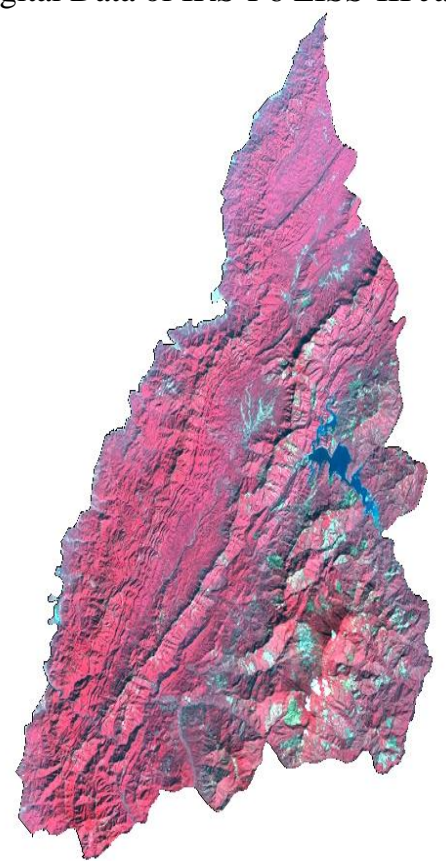

Fig. 3: Digital Data of IRS-P6 LISS-III Jan.2008, Wokha 


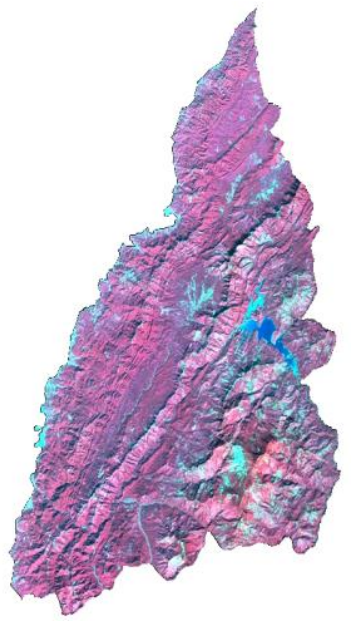

III. Methodology

The present methodology of forest cover mapping from satellite data using Arc GIS and ERDAS Imagine software's on 1:50,000 scales involves the following steps:

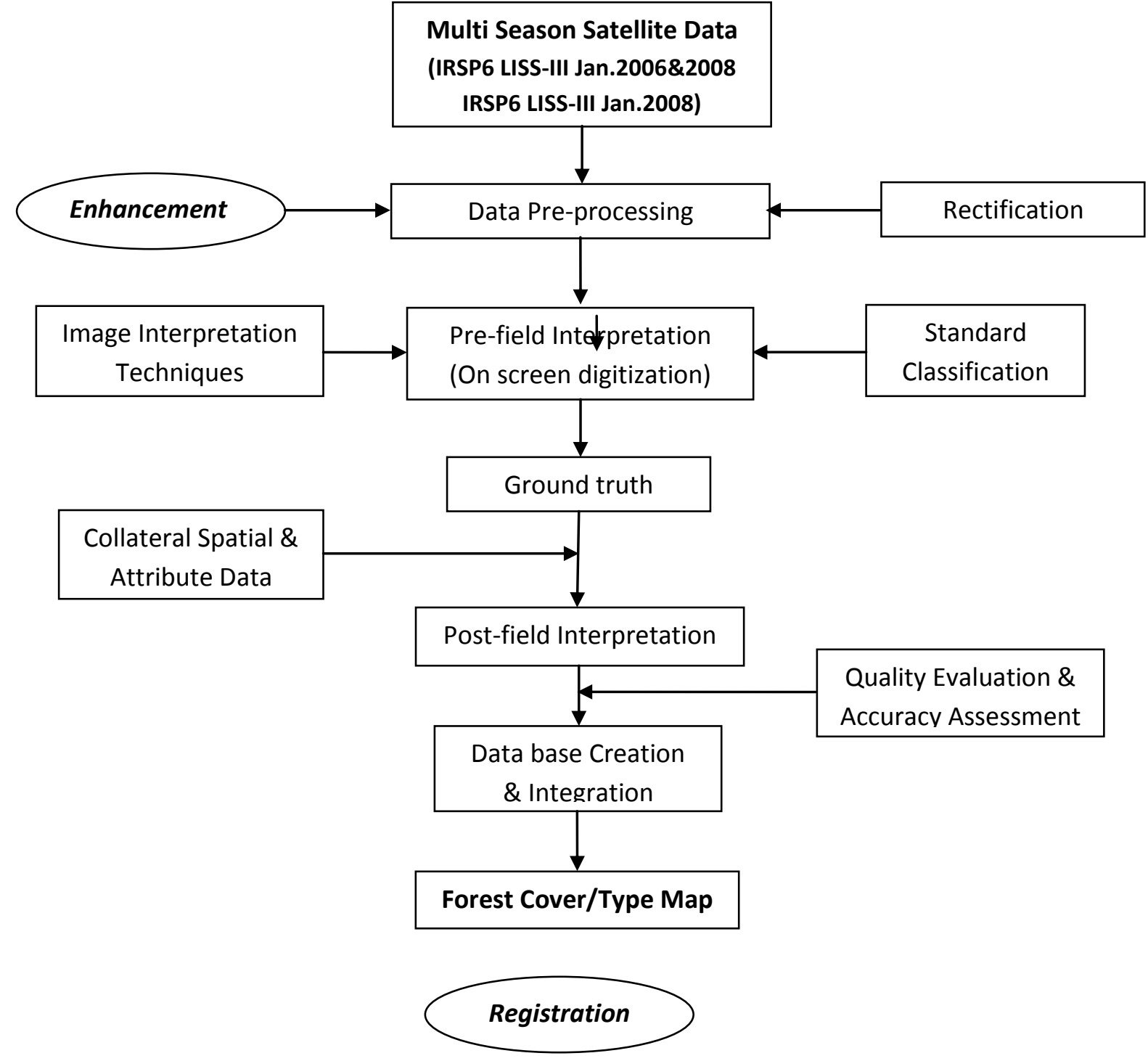

Fig. 4: Flow chart of Forest cover/Type mapping using remote sensing 


\section{Forest Types}

As stated above Wokha situated in the extreme part of the country and on the southern extension of the Himalayas is richly gifted with a wide variety of forest types. The types of climate and also the types of soil can be ascribed as the main factors that provide congeniality to the richness of the prevailing evergreen vegetation/ forest cover in the state. The major forest types in the state are as under:

1. Forest-Evergreen/Semi-Evergreen

It is characterized by thick and dense canopy of tall trees, which predominantly remain green throughout the year. It includes both coniferous and tropical broadleaved evergreen species. Semi-evergreen is a forest type that includes a combination of evergreen and deciduous species with the former dominating the canopy cover.

a. Forest-Evergreen/Semi-Evergreen-Dense

All the areas where the canopy cover/density is more than $40 \%$ are included in this category.

b. Forest-Evergreen/Semi-Evergreen-Open

The type of this forest includes all the areas where the canopy cover/density is between $10-40 \%$.

2. Forest-Deciduous

This forest type is predominantly composed of species, which shed their leaves once a year, especially during summer.

\section{a. Forest-Deciduous-Dense}

The forest of this type falls within all the areas where the canopy cover/density is more than $40 \%$.

b. Forest-Deciduous-Open

All the areas where the canopy cover/density is between 10-40\% are marked by this forest type.

\section{Bamboo Mixed Forest}

Forest cover mixed with bamboo comes under this type.

4. Scrub Land

A land, which is generally prone to deterioration due to erosion.

\section{a. Scrub Land-Dense Scrub}

This type generally occurs in the areas which possess shallow and skeleton soils with scrub dominating the landscape.

b. Scrub Land-Open Scrub

Similar to the above excepting that it is sparse vegetation devoid of scrub with thin soil cover.

\section{Water-bodies}

These include lakes/ponds-perennial, reservoir/tanks-perennial, river/stream-perennial

6. Non-Forest/Miscellaneous

It includes Jhum land, cropland, fallow land, abandoned Jhum, barren rocky/stony waste, natural/semi natural grassland \& grazing land and settlement.

Fig. 5: Classified image of Forest Cover, Wokha

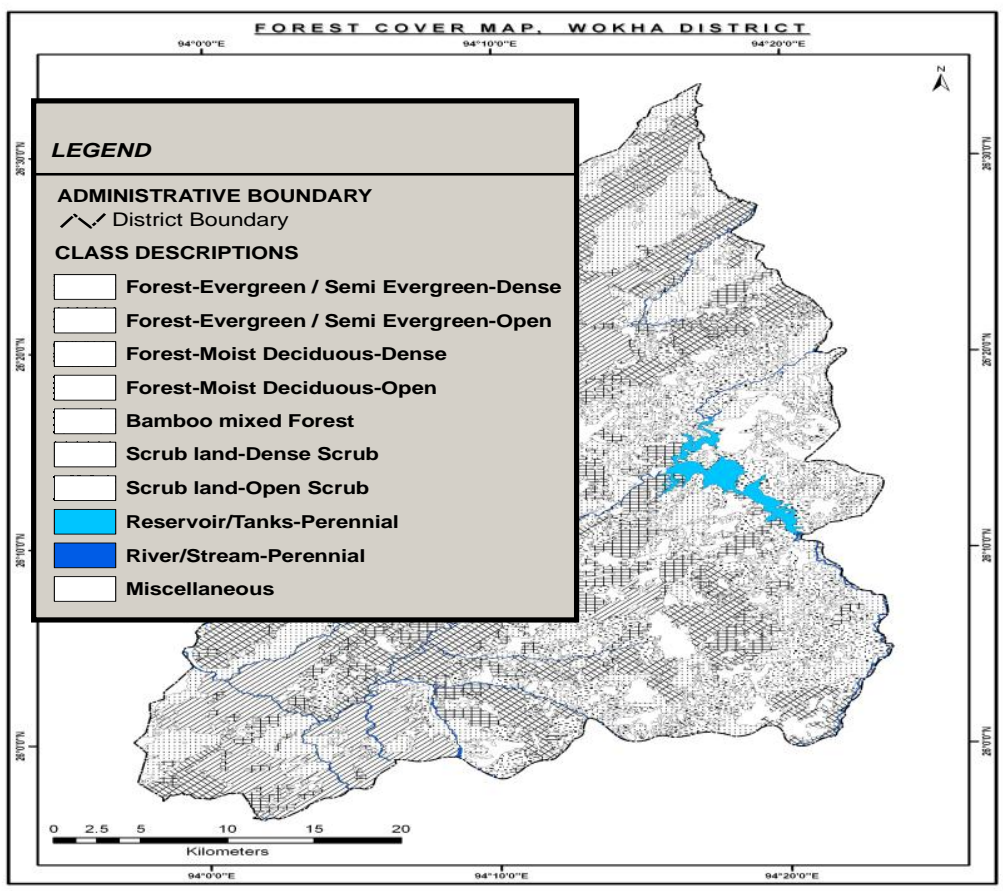


Table 1:

\begin{tabular}{|c|l|r|}
\hline \multicolumn{3}{|c|}{ AREA STATISTICS - WOKHA DISTRICT } \\
\hline SL.NO. & \multicolumn{1}{|c|}{ CLASS DESCRIPTIONS } & AREA (sq.km) \\
\hline 1 & Forest-Evergreen / Semi Evergreen-Dense & 0.47 \\
\hline 2 & Forest-Evergreen / Semi Evergreen-Open & 201.17 \\
\hline 3 & Forest-Moist Deciduous-Dense & 326.93 \\
\hline 4 & Forest-Moist Deciduous-Open & 464.55 \\
\hline 5 & Bamboo mixed Forest & 0.84 \\
\hline 6 & Scrub land-Dense Scrub & 167.81 \\
\hline 7 & Scrub land-Open Scrub & 180.24 \\
\hline 8 & Reservoir/Tanks-Perennial & 16.82 \\
\hline 9 & River/Stream-Perennial & 14.46 \\
\hline 10 & Miscellaneous & 259.43 \\
\hline & & 1632.73 \\
\hline
\end{tabular}

Note: Miscellaneous Class includes - Settlement, Crop Land, Fallow Land, Current Jhum, Abandoned Jhum, etc.

The area is characterized by unique physiographic features of the southern Himalayas like lofty mountainous ranges, hills, narrow valleys limited expanse of plains, salubrious climatic conditions etc. is provided with rich vegetation cover and its types. Wokha forest cover mapping based on data provided by National Remote Sensing Centre (NRSC), multi season digital data of IRS-P6 LISS-III Jan.2006 \& IRS-P6 LISS-III Jan.2008 (resolution 23.5m) is 1342.01 sq.km, is about $83 \%$ of the Wokha geographical area. It is found that $12.3 \%$ under Forest-Evergreen/Semi-Evergreen, 48.61\% under Forest Moist Decidious and Scrub land accounts for $21.37 \%$. Bamboo mixed forest has the lowest area of $1 \%$ of the total geographical. Thus, it is found that $82 \%$ of the area is under forest cover. Forest occupies an area of approximately 25291.97 hac, of which government forest accounts for $5.10 \%$. The private forests vested with the villagers are being haphazardly and unscientifically exploited without having any concern for future generations. In Reserved Forests too, where there is imposition of ban on felling and cutting of trees, there is a large scale illegal exploitation harming the ecological balance. In recent years there is, however, a perceptible change in the traditional perception of the people about their physical environment. In many areas people have started planting trees in the jhum lands to help preserve the land and compensate the removals from the forests areas.

\section{Suggestions}

- Mapping of forest encroachments.

- Preparation of soil conservation plan based on identified environmental problems.

- Temporal changes detection of the extent of shifting cultivation to ascertain change and its subsequent monitoring.

- Categorisation of various types of land use/land cover pattern using remote sensing data.

\section{Conclusion}

The present study points out that Forest-Evergreen/Semi Evergreen Dense, Forest-Evergreen/Semi Evergreen Open, Forest-Forest Blank, Forest-Forest Plantation, Forest-Moist Deciduous-Dense, Scrub landDense Scrub, Bamboo Mixed Forest, etc. are the forest types in the study area and (b) there are also a large extent of scrub forests indicating that heavy damage has been done to the virgin forests.

Since local population is intricately involved with the forests for their sustenance, be it for agriculture, timber, day to day use items or medicinal plants etc. forest products are their main source of economy. As the mainstay of the people is dependent on forest, destruction of forests is imminent which will put valuable spaces at stake. Due to the primitive methods of cultivation i.e slash and burn the rich biodiversity of the state is thinning out in great rapidity. Most of the species, both flora and fauna, appear to be endangered due to heavy biotic pressure, human interference and reckless deforestation.

Results of change detection analysis are very useful to take necessary action to conserve the forests. Despite the fact that there is change in forest cover invariably in all the classes the increase in some of the forest types has been observed. Dense forest cover of all the forest types seems to have turned into open and degraded forest covers. The forest areas near the road systems and the hamlets have been highly degraded. The weighted 
overlay analysis which reveals the forest areas, prone to degradation under different categories as observed on 1: 50,000 scales would be a good source of information for planners, decision-makers, administrators etc. for effective conservation of forests and their products. About $85 \%$ of the forest is under the low-risk category. Necessary protected measures on priority basis need to be given to the high risk forests areas while planning for conservation and protection of the forest from harmful and illegal human interference.

\section{References:}

[1]. Agrawala, U.P. (1990) Forests of India, Oxford and IBH Publishing Co. Pvt. Ltd., Janpath, New Delhi

[2]. Anon. (1979):Satellite Remote Sensing Survey of Natural Resources Nagaland, 1979: Project Report by NRSA,Hyderabad,

[3]. Anon. (2005,2008): : Annual Administrative Report, Department of Forest, Environment, Ecology andWildlife, Govt. of Nagaland, Kohima.

[4]. Anon.(2007): Statistical Handbook of Nagaland, Directorate of Economics \& Statistics, Government of Nagaland, Kohima.

[5]. Anon.( 2002,2009):State of Forest Report, Forest Survey of India ,Ministry of Environment \& Forests, Kaulagarh Road, Dehran Dun.

[6]. Anon.(2003,2005): Ministry of Environment and Forest, Dehradun, State of Forest Report, Forest Survey of India.

[7]. Anon.(2006): Ministry of Environment and Forest, Dehradun, Forest Atlas of India, Forest Survey of India.

[8]. Areendran Gand Prakash Rao (2006): Indira Gandhi Conservation Monitoring Centre; Vegetation Types of the Southern Eastern Ghats; A Remote Sensing Perspective; WWF India 172 B, Lodi Estate, New Delhi -110003.

[9]. Craswell,E.T., Sajjapongse,A., Hpwlett, D.J.P., Dowling, A.J., 1997. Agroforestry in the management of slopping lands in Asia and the Pacific,Agroforestry System, 38:121-137.

[10]. Directorate of Economics \& Statistics, Government of Nagaland, Kohima: Statistical Handbook of Nagaland,2012.

[11]. Franklin. E. Steven (2001) Remote Sensing for Sustainable Forests Management, Lewis Publishers, Washington D.C.

[12]. Gupta Vishal, 2005. Jhum Cultivation practices of Bangnis (Nishis) of Arunachal Pradesh, Indian Journal of traditional knowledge.

[13]. Mather, S. Alexander (1990), Global forests Resources, Timber Press Portland, Oregon.

[14]. Surendra Singh(1999): A Resource Atlas of Arunachal Pradesh, Arunachal Pradesh, Itanagar. 